\title{
Pengaruh Religiusitas dan Fundraising terhadap Minat Berwakaf Uang dengan Kesadaran Sebagai Variabel Intervening pada Pegawai Kantor Wilayah Kementerian Agama Provinsi Sumatera Selatan
}

\author{
Dwi Kurniawati $^{1 *}$, Cholidi Zainuddin ${ }^{1}$, Rika Lidyah ${ }^{1}$ \\ ${ }^{1}$ UIN Raden Fatah Palembang, Indonesia
}

\begin{abstract}
Abstrak: Penelitian ini bertujuan untuk mengetahui seberapa besarnya minat Pegawai Kantor Wilayah Kementerian Agama Provinsi Sumatera Selatan dalam berwakaf uang. Dalam penelitian ini data dikumpulkan dengan menyebarkan kuesioner terhadap 50 pegawai menggunakan metode insidental Sampling untuk mengetahui tanggapan responden dengan variabel yang ada. Analisis dengan menggunakan metode Structural Equation Modeling (SEM) berbasis Partial Least Square (PLS). Hasil analisis menunjukkan bahwa religiusitas tidak terdapat pengaruh terhadap minat berwakaf uang, fundraising berpengaruh positif dan signifikan terhadap minat berwakaf uang, religiusitas berpengaruh positif dan signifikan terhadap kesadaran pegawai berwakaf uang, fundraising berpengaruh positif dan signifikan terhadap kesadaran, dan variabel kesadaran berpengaruh signifikan dalam memediasi antara religiusitas terhadap minat berwakaf dan fundraising terhadap minat wakaf.
\end{abstract}

Kata Kunci: religiusitas, fundraising, kesadaran, minat, wakaf uang

\begin{abstract}
This study aims to determine how much interest in the Regional Office of the Ministry of Religion of South Sumatra Province employees in cash waqf. In this study, data were collected by distributing questionnaires to 50 employees using the incidental sampling method to determine respondents' responses to existing variables. Analysis using Structural Equation Modeling (SEM) based on Partial Least Square (PLS). The results of the analysis show that religiosity has no effect on interest in cash waqf, fundraising has a positive and significant effect on interest in cash waqf, religiosity has a positive and significant effect on employee awareness of cash waqf, fundraising has a positive and significant effect on awareness, and awareness variable has a significant effect on mediating between religiosity on interest in waqf and fundraising on interest in waqf.
\end{abstract}

Keywords: religiosity, fundraising, awareness, interest, cash waqf

\section{Pendahuluan}

Pengelolaan dan pengembangan wakaf yang ada di Indonesia memerlukan komitmen bersama pemerintah, ulama dan masyarakat. Selain itu juga harus dirumuskan kembali mengenai berbagai hal yang berkenaan dengan wakaf, termasuk harta yang diwakafkan, peruntukkan wakaf dan nadzir serta pengelolaan wakaf secara profesional. Selanjutnya wakaf harus diserahkan kepada orang-orang atau suatu badan, khusus yang mempunyai kompetensi memadai sehingga bisa mengelola secara profesional dan amanah (Ibrahim, 2020).

Di tengah problem sosial masyarakat Indonesia dan tuntutan akan kesejahteraan ekonomi

\footnotetext{
* Corresponding Author: Dwi Kurniawati (dwiidjuhann@gmail.com). UIN Raden Fatah Palembang, Indonesia
} 
akhir-akhir ini, keberadaan wakaf uang menjadi sangat strategis. Wakaf uang sebagai salah satu aspek ajaran Islam yang berdimensi spiritual, wakaf uang juga merupakan ajaran yang menekankan pentingnya kesejahteraan ekonomi (dimensi sosial) dan kesejahteraan umat (Nurfaidah, 2016).

Wakaf uang yang didefinisikan sebagai aset yang disumbangkan untuk kemanusiaan dalam jangka waktu yang relatif lama. Wakaf uang memiliki dua fungsi yaitu fungsi ritual dan sosial ekonomi. Fungsi ritualnya, wakaf adalah sebagai implementasi iman seseorang dalam bentuk kesadaran beramal shaleh yang dapat diharapkan pahalanya mengalir terus menerus hingga yang besangkutan telah meninggal dunia. Sedangkan fungsi sosial ekonominya, sebagai bentuk solidaritas yang menjadi kontributif terhadap kesejahteraan masyarakat yang abadi (dana sosial abadi) (Muzarie, 2011).

Tabel 1. Potensi Wakaf Uang di Indonesia

\begin{tabular}{|c|c|c|c|c|}
\hline $\begin{array}{c}\text { Tingkat } \\
\text { penghasilan/Bu } \\
\text { lan }(\mathbf{R p})\end{array}$ & $\begin{array}{c}\text { Jumla } \\
\text { h } \\
\text { Musli } \\
\text { m }\end{array}$ & $\begin{array}{c}\text { Tarif } \\
\text { Wak } \\
\text { af } \\
\text { /bln }\end{array}$ & $\begin{array}{c}\text { Potensi } \\
\text { Wakaf } \\
\text { Uang/b } \\
\text { ln }\end{array}$ & $\begin{array}{c}\text { Potensi } \\
\text { Wakaf } \\
\text { Uang/t } \\
\text { hn }\end{array}$ \\
\hline Rp 1 Juta & 4 Juta & $\begin{array}{c}\mathrm{Rp} \\
5.000 \\
-\end{array}$ & $\begin{array}{l}\text { Rp } 20 \\
\text { Milyar }\end{array}$ & $\begin{array}{l}\text { Rp } 240 \\
\text { Milyar }\end{array}$ \\
\hline$\underset{\text { juta }}{\text { Rp } 2 \text { juta - Rp } 3}$ & 3 Juta & $\begin{array}{c}\mathrm{Rp} \\
10.00 \\
0\end{array}$ & $\begin{array}{l}\text { Rp } 30 \\
\text { Milyar }\end{array}$ & $\begin{array}{l}\text { Rp } 300 \\
\text { Milyar }\end{array}$ \\
\hline$\underset{\text { juta }}{\text { Rp } 3 \text { juta - Rp } 5}$ & 2 Juta & $\begin{array}{c}\mathrm{Rp} \\
50.00 \\
0\end{array}$ & $\begin{array}{l}\text { Rp } 100 \\
\text { Milyar }\end{array}$ & $\begin{array}{l}\text { Rp 1,2 } \\
\text { Triliun }\end{array}$ \\
\hline $\begin{array}{l}\text { Rp } 5 \text { juta - Rp } \\
10 \text { juta }\end{array}$ & 1 Juta & $\begin{array}{c}\mathrm{Rp} \\
100.0 \\
00,-\end{array}$ & $\begin{array}{l}\text { Rp } 100 \\
\text { Milyar }\end{array}$ & $\begin{array}{l}\text { Rp 1,2 } \\
\text { Triliun }\end{array}$ \\
\hline Total & & & & $\begin{array}{l}\mathrm{Rp} 3 \\
\text { Triliun }\end{array}$ \\
\hline
\end{tabular}

Sumber: Nasution (2005)

Pada Tabel 1. merupakan perkiraan potensi wakaf di Indonesia yang mencapai Rp 3 triliun per tahunnya akan tetapi realitanya hanya 215 miliar
(Amin, 2020). Rendahnya edukasi mengenai wakaf uang tersebut menimbulkan ketidaktertarikan pada wakaf uang sehingga belum mencapai potensi yang diperkirakan.

Indonesia merupakan negara muslim terbanyak dengan pesantren, dan madrasah akan tetapi realitanya literasi mengenai wakaf sangat rendah hanya 57,75\% (Amin, 2020). Pada tahun 2020, kementerian agama mulai menggalakkan rencana strategi dan kebijakan mengenai wakaf uang dengan melaksanakan wakaf uang pada pegawai dan persentase peningkatan pengelolaan aset wakaf produktif bagi nazhir. Inisiasi gerakan wakaf nasional pegawai di kementerian agama salah satunya dengan memberikan sosialisasi dan literasi terkait wakaf kepada pegawai di Indonesia dengan upaya tersebut diharap dapat menumbuhkan minat bagi pegawai atau wakif lainnya untuk berwakaf uang dan mendorong nazhir untuk mengoptimalkan aset wakaf produktif melalui BWI dan forum lembaga wakaf produktif.

Minat berwakaf uang dipengaruhi oleh berbagai faktor salah satunya adalah faktor religiusitas. Religiusitas berkaitan dengan pemahaman dan pengetahuan seseorang kepada agama baik berupa perintah maupun larangan yang merupakan ajaran-ajaran agama (Jalaludin, 1995). Dalam hal ini jika semakin tinggi religiusitasnya maka dapat diartikan salah satu faktor keberhasilan dalam pengumpulan dana wakaf. Selain religiusitas, faktor penghimpunan dana (fundraising) wakaf merupakan proses mempengaruhi calon wakif agar berkeinginan melakukan amal kebajikan dalam bentuk penyerahan uang sebagai wakaf maupun sumbangan pengelolaan harta wakaf. Kegiatan pengerahan dana ini sangat berhubungan dengan kemampuan perseorangan, organisasi, badan hukum untuk mengajak dan memengaruhi orang lain sehingga menimbulkan kesadaran, kepedulian, 
dan motivasi untuk melakukan wakaf (Rozalinda, 2015).

\section{Metode Penelitian}

Metode analisis yang digunakan dalam penelitian inii yaitu analisis jalur (path analysis). Metode analisis ini dapat digunakan untuk mengetahui besarnya pengaruh hubungan religiusitas, fundraising terhadap minat berwakaf uang pegawai kementerian agama sumatera selatan dengan kesadaran sebagai variabel intervening. Data yang digunakan dalam penelitian ini adalah data primer dengan teknik pengumpulan data dilakukan dengan penyebaran kuesioner. Populasi penelitian adalah pegawai kantor wilayah Kementerian Agama Sumatera selatan yang sesuai kriteria untuk dijadikan responden. Kriteria yang digunakan meliputi sisi religiusitas, fundraising terhadap minat berwakaf uang. Penentuan jumlah sampel yang di tentukan berdasarkan perhitungan melalui rumus Hair et al adalah tergantung pada jumlah indikator dikali 5 sampai 101. Jumlah sampel dalam penelitian ini adalah 50 responden, Penelitian ini menggunakan teknik insidental sampling. Pada penelitin ini analisis data yang digunakan adalah uji validitas, uji reliailitas dan uji hipotesis dengan SEM (Structural Equation Modeling).

\section{Hasil Penelitian dan Pembahasan}

\section{Pengujian Model Pengukuran (Measurement Model)}

a. Outer Loading Factor

Nilai loading factor sebesar 0,50 atau lebih dianggap memiliki validasi yang cukup kuat untuk menjelaskan konstruk laten. Nilai outer loading awal pada variabel religiusitas, fundraising, minat berwakaf dan kesadaran dapat dilihat pada Tabel berikut Menurut Yamin dan Kurniawan indikator yang memiliki nilai loading factor antara 0.5 -0.6 dapat diterima.

Tabel 2. Outer Loading

\begin{tabular}{|c|c|c|c|c|}
\hline Item & Kesadaran & $\begin{array}{c}\text { Minat } \\
\text { Berwakaf }\end{array}$ & Religiusitas & Fundraising \\
\hline $\mathbf{Z 1}$ & 0.717 & & & \\
\hline $\mathbf{Z 2}$ & 0.869 & & & \\
\hline $\mathbf{Z 3}$ & 0.883 & & & \\
\hline $\mathbf{Z 4}$ & 0.885 & & & \\
\hline $\mathbf{Z 5}$ & 0.795 & & & \\
\hline $\mathrm{Z6}$ & 0.870 & & & \\
\hline X1.1 & & & 0.753 & \\
\hline $\mathrm{X} 1.2$ & & & 0.770 & \\
\hline $\mathrm{X} 1.3$ & & & 0.738 & \\
\hline X1.4 & & & 0.703 & \\
\hline $\mathrm{X} 1.5$ & & & 0.893 & \\
\hline X1.6 & & & 0.799 & \\
\hline $\mathrm{X} 1.7$ & & & 0.893 & \\
\hline X1.8 & & & 0.829 & \\
\hline X1.9 & & & 0.885 & \\
\hline $\mathrm{X} 2.1$ & & & & 0.886 \\
\hline $\mathrm{X} 2.2$ & & & & 0.928 \\
\hline $\mathrm{X} 2.3$ & & & & 0.878 \\
\hline $\mathrm{X} 2.4$ & & & & 0.882 \\
\hline Y1 & & 0.824 & & \\
\hline Y2 & & 0.877 & & \\
\hline $\mathbf{Y 3}$ & & 0.831 & & \\
\hline Y4 & & 0.893 & & \\
\hline
\end{tabular}

Berdasarkan tabel 2, menunjukkan bahwa semua variabel penelitian memiliki nilai-nilai outer loading dari setiap item pertanyaan > loading faktor 0,50, yang artinya dapat diterima atau lebih dianggap memiliki validitas yang cukup kuat untuk menjelaskan konstruk laten.

b. Uji Reabilitas

Instrument realiabilitas dalam penelitian ini diukur dengan dua Kriteria yaitu nilai composite reliability dan cronbach's alpha. Penggunaan cronbach's alpha cenderung menaksirkan lebih 
rendah reliabilitas variabel dibandingkan composite reliability sehingga disarankan untuk menggunakan composite reliability menurut haryono (2017). Sebuah konstruk dapat dikatakan reliabel apabila nilai cronbach's alpha lebih 0,70 sedangkan menurut Ghozali (2005) variabel dikatakan reliabel jika nilai composite reliability di atas 0,70 .

Tabel 3. Construct reliability dan validity

\begin{tabular}{|c|c|c|}
\hline & $\begin{array}{c}\text { Cronbach's } \\
\text { Alpha }\end{array}$ & rho_A \\
\hline Religiusitas & 0.933 & 0.941 \\
\hline Kesadaran & 0.915 & 0.920 \\
\hline $\begin{array}{l}\text { Minat } \\
\text { Berwakaf }\end{array}$ & 0.879 & 0.880 \\
\hline Fundraising & 0.916 & 0.919 \\
\hline \multicolumn{3}{|c|}{$\begin{array}{l}\text { Sumber: Hasil Penelitian diolah dengan smartPLS 3.0, } 2021 \\
\text { Berdasarkan tabel 3, menunjukan bahwa } \\
\text { semua variabel penelitian memiliki nilai } \\
\text { cronbach's alpha dan composite reliability di atas } \\
0,70 \text {. Oleh karena itu indikator yang digunakan } \\
\text { dalam variabel penelitian ini dikatakan reliable. } \\
\text { Sedangkan validitas mengunakan nilai average } \\
\text { variance extracted (AVE) dengan nilai batasan } \\
\text { diatas } 0,50 \text { pada tabel IV.10 terlihat bahwa semua } \\
\text { variabel memiliki nilai AVE diatas } 0,50 \text {. Hal ini } \\
\text { dapat diartikan bahwa keseluruhan indikator dan } \\
\text { variabel dinyatakan valid. }\end{array}$} \\
\hline
\end{tabular}

Uji korelasi diskriminan dilakukan untuk melihat korelasi antara konstruk dengan konstruk lainya. Jika nilai akar kuadrad (square root of average) AVE setiap konstruk lebih besar daripada nilai korelasi antara konstruk dengan konstuk lainya dalam model maka dapat disimpulkan bahwa konstruk memiliki tingkat validitas yang baik.

Tabel 4. Nilai Discriminant Validity

\begin{tabular}{lcccc}
\hline & Fundraising & Kesadaran & $\begin{array}{c}\text { Minat } \\
\text { Berwakaf }\end{array}$ & Religiusitas \\
\hline Religiusitas & 0.894 & & & \\
Kesadaran & 0.762 & 0.839 & & \\
$\begin{array}{l}\text { Minat } \\
\text { Berwakaf }\end{array}$ & 0.770 & 0.870 & 0.857 & \\
Fundraising & 0.632 & 0.682 & 0.700 & 0.810 \\
& & & & \\
\hline
\end{tabular}

Sumber: Hasil penelitian diolah dengan smartPLS 3.0, 2021

Composite 4 , Rerbandingan nilai akar AVE

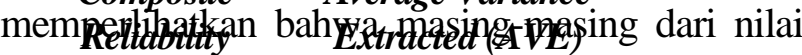
tersebut lebih besar dibandingkan dengan korelasi antar variabel lainya, sehingga dapat ditarik kesimpulan bahwa semua variabel laten dalam penelitian ${ }^{9}$ memiliki construct validity dan discriminant validity yang Baie 4

\section{PengujôtgntStruktural Moded9}

Pengujian structural model dilakukan untuk melihat hubungan antara konstruk, nilai signifikansi dan $R$-square dari model penelitian. Nilai $R$-square dapat digunakan untuk menilai pengaruh variabel independen tertentu terhadap variabel dependen. Nilai estimasi $R$-square dapat dilihat pada Tabel berikut ini.

Tabel 5. Nilai $R$-square

\section{$R$-square $\quad$ Adjusted R-square}

$\begin{array}{cll}\text { Kesadaran } & 0.647 & 0.632 \\ \text { Minat } & 0.797 & 0.783\end{array}$

Berwakaf

Berdasarkan tabel 5 diketahui bahwa Nilai $R$ square untuk variabel kesadaran sebesar 0,647 atau $64,7 \%$ yang dapat di interprestasikan bahwa besarnya faktor yang mempengaruhi kesadaran dapat dijelaskan oleh faktor religiusitas dan fundraising sedangkan sebesar 35,3\% dipengaruhi oleh variabel lain diluar penelitian ini. Nilai $R$ - 
Pengaruh Religiusitas dan Fundraising

square untuk variabel minat berwakaf sebesar 0,797 atau $79,7 \%$ yang dapat di interprestasikan bahwa besarnya faktor yang mempengaruhi minat berwakaf uang dapat dijelaskan oleh faktor religiusitas dan fundraising sedangkan sebesar 20,3\% dipengaruhi oleh variabel lain diluar penelitian ini.

\section{Uji Hipotesis}

Diterima atau tidaknya sebuah hipotesis yang diajukan, perlu dilakukan pengujian hipotesis dengan menggunakan fungsi Bootstripping pada SmartPLS 3.0. hipotesis diterima pada saat tingkat signifikan lebih kecil dari 0,05 atau t-value melebihi nilai kritisnya. Nilai $\mathrm{t}$ statistics untuk tingkat signifikansi 5\% sebesar 1,96. dapat dilihat pada gambar path diagram serta tabel Hasil Path Coefficient berkut ini:

Gambar 1. Path Diagram

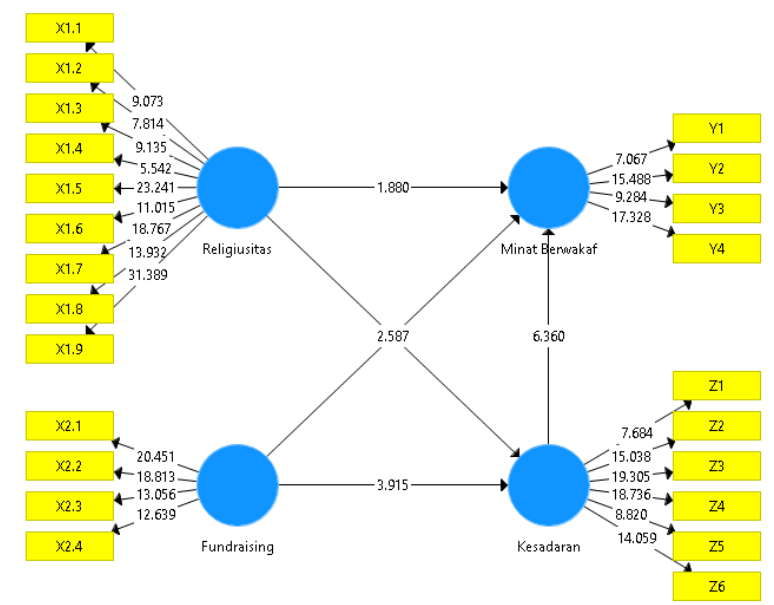

Sumber: Hasil penelitian diolah dengan smartPLS 3.0, 2021
Tabel 6. Uji Hipotesis

Hasil Path Coefficient

\begin{tabular}{|c|c|c|c|c|c|c|c|}
\hline & $\begin{array}{l}\text { Variabel/Kon } \\
\text { struk }\end{array}$ & $\begin{array}{c}\text { Origi } \\
\text { nal } \\
\text { Samp } \\
\text { el }\end{array}$ & $\begin{array}{c}\text { Sam } \\
\text { pel } \\
\text { Mea } \\
\text { n }\end{array}$ & $\begin{array}{l}\text { Standa } \\
\text { rd } \\
\text { Deviati } \\
\text { on } \\
\text { (STDE } \\
\text { V) }\end{array}$ & $\begin{array}{c}\mathrm{T} \\
\text { Statistik } \\
(\mathrm{O} / \mathrm{STD} \\
\text { EV) }\end{array}$ & $\begin{array}{c}\mathrm{P} \\
\text { Valu } \\
\text { es }\end{array}$ & Hasil \\
\hline $\begin{array}{c}\mathrm{H} \\
1\end{array}$ & $\begin{array}{l}\text { Religiusitas } \\
\text { Kesadaran }\end{array}$ & 0.334 & 0.365 & 0.134 & 3.945 & $\begin{array}{c}0.00 \\
0\end{array}$ & $\begin{array}{c}\text { Diteri } \\
\text { ma }\end{array}$ \\
\hline $\begin{array}{l}\mathrm{H} \\
2\end{array}$ & $\begin{array}{l}\text { Fundraising } \\
\text { Kesadaran }\end{array}$ & 0.551 & 0.515 & 0.140 & 3.945 & $\begin{array}{c}0.00 \\
0\end{array}$ & $\begin{array}{c}\text { Diteri } \\
\text { ma }\end{array}$ \\
\hline $\begin{array}{l}\mathrm{H} \\
3\end{array}$ & $\begin{array}{l}\text { Religiusitas } \\
\text { Minat } \\
\text { Berwakaf } \\
\text { Uang }\end{array}$ & 0.115 & 0.154 & 0.085 & 1.829 & $\begin{array}{c}0.06 \\
8\end{array}$ & $\begin{array}{c}\text { Ditola } \\
\mathrm{k}\end{array}$ \\
\hline $\begin{array}{l}\mathrm{H} \\
4\end{array}$ & $\begin{array}{l}\text { Fundraising } \\
\text { Minat } \\
\text { Berwakaf } \\
\text { Uang }\end{array}$ & 0.215 & 0.189 & 0.098 & 2.183 & $\begin{array}{c}0.03 \\
0\end{array}$ & $\begin{array}{c}\text { Diteri } \\
\text { ma }\end{array}$ \\
\hline $\begin{array}{l}\mathrm{H} \\
5\end{array}$ & $\begin{array}{l}\text { Kesadaran } \\
\text { Minat } \\
\text { Berwakaf } \\
\text { Uang }\end{array}$ & 0.600 & 0.620 & 0.093 & 6.441 & $\begin{array}{c}0.00 \\
0\end{array}$ & $\begin{array}{c}\text { Diteri } \\
\text { ma }\end{array}$ \\
\hline $\begin{array}{l}\mathrm{H} \\
6\end{array}$ & $\begin{array}{l}\text { Religiusitas } \\
\text { Kesadaran } \\
\text { Minat } \\
\text { Berwakaf } \\
\text { Uang }\end{array}$ & 0.200 & 0.227 & 0.097 & 2.169 & $\begin{array}{c}0.00 \\
1\end{array}$ & $\begin{array}{c}\text { Diteri } \\
\text { ma }\end{array}$ \\
\hline $\begin{array}{l}\mathrm{H} \\
7\end{array}$ & $\begin{array}{l}\text { Fundraising } \\
\text { Kesadaran } \\
\text { Minat } \\
\text { Berwakaf } \\
\text { Uang }\end{array}$ & 0.331 & 0.319 & 0.097 & 3.414 & $\begin{array}{c}0.03 \\
1\end{array}$ & $\begin{array}{c}\text { Diteri } \\
\text { ma }\end{array}$ \\
\hline
\end{tabular}

Dari path coefficient di atas dapat dilihat nilai original sampel, $\mathrm{p}$ value atau $\mathrm{t}$ statistics yang digunakan sebagai acuan untuk mengambil keputusan hipotesis diterima atau hipotesis ditolak. Hipotesis dapat diterima jika nilai $\mathrm{t}$ statistics $>\mathrm{t}$ tabel atau $\mathrm{p}$ value $<0,05$.

\section{Pembahasan}

Dasar pemikiran dari penelitian ini adalah untuk memindai dan mengamati faktor-faktor determinan dari minat berwakaf uang pegawai kementerian agama sumatera selatan yang terdiri dari religiusitas, fundraising dan kesadaran.

\section{H1: Religiusitas Berpengaruh Terhadap Kesadaran}

Dari hasil penelitian hipotesis pertama terhadap pengaruh antara religiusitas terhadap kesadaran berwakaf uang. Hal ini sesuai dengan 
hasil path coefficients dengan nilai t-statistik religiusitas terhadap kesadaran $2.494<1.96$ atau dapat dilihat $p$ value nya yang bernilai $0.533>0.05$. nilai original sampel adalah positif sebesar 0.334 yang menunjukan bahwa arah hubungan antara religiusitas terhadap kesadaran adalah positif.

Hasil penelitian ini sesuai dengan penelitian sebelumnya oleh Istikomah dan Zahrok Nur Ulya (2017) dimana dibuktikan dengan hasil uji statistik religiusitas berpengaruh terhadap kesadaran etis akuntan. Tingkat religiusitas yang tinggi memberikan pemahaman seseorang terhadap norma-norma syari'ah, khususnya terkait wakaf. Religiusitas menyangkut keyakinan, akhlak dan pengetahuan, sehingga dapat dikatakan bahwa semakin baik sikap seseorang terhadap suatu objek (berwakaf uang), maka semakin tinggi pula kemungkinan seseorang untuk melakukan hal-hal yang sesuai dengan objek tersebut.

\section{H2: Fundraising berpengaruh terhadap kesadaran}

Dari hasil penelitian hipotesis kedua terdapat pengaruh fundraising terhadap kesadaran, Hal ini sesuai dengan Nilai t-statistik fundraising terhadap kesadaran $3.945>1.96$ atau dapat dilihat $p$ value nya yang bernilai $0.000<0.05$. nilai original sampel adalah positif signifikan. Hasil penelitian ini sesuai dengan penelitian dari Pipit Puji Noor Fazri (2019) menunjukkan bahwa fundraising berpengaruh terhadap kesadaran. Faktor penghambat dalam pelaksanaan program penghimpunan dana antara lain kurangnya kesadaran masyarakat akan pemanfaatan dana wakaf.

\section{H3: Religiusitas berpengaruh terhadap minat berwakaf uang}

Dari hasil penelitian tidak berpengaruh antara religiusitas dan minat berwakaf uang. Hal ini sesuai dengan hasil path coefficients dengan nilai t- statistik religiusitas terhadap minat berwakaf uang sebesar $1.829<1.96$ atau dapat dilihat $p$ value yang bernilai $0.065<0.05$. nilai original sampel adalah positif sebesar 0.115 yang menunjukan arah hubungan antara religiusitas terhadap minat berwakaf uang adalah negatif.

Hasil penelitian ini sejalan dengan penelitian Hanwar Ahmad Sidiq (2015) dalam penemuannya menjelaskan tidak terdapat hubungan antara religiusitas dan minat. Dalam hal ini diindikasi bahwa minat merupakan dorongan kuat bagi seseorang untuk melakukan segala sesuatu dalam mewujudkan pencapaian tujuan dan cita-cita yang menjadi keinginannya. Minat dapat timbul karena adanya faktor eksternal dan juga adanya faktor internal.

\section{H4: Fundraising berpengaruh terhadap minat berwakaf uang}

Hasil penelitian terhadap pengaruh fundraising terhadap minat berwakaf uang. dalam penelitiannya menemukan bahwa fundraising berpengaruh positif dan signifikan terhadap minat, Hal ini sesuai dengan hasil path coefficients dengan nilai t-statistik religiusitas terhadap kesadaran 2.183 $<1.96$ atau dapat dilihat $\mathrm{p}$ value nya yang bernilai $0.000>0.05$. nilai original sampel adalah positif sebesar 0.215 yang menunjukan arah hubungan antara fundraising terhadap minat berwakaf uang.

Penelitian ini sesuai dengan penelitian sebelumnya oleh Nur Alfisyah (2018), menyatakan bahwa fundraising memberikan pengaruh yang signifikan terhadap minat. Lembaga pengelola dalam menjalankan tugasnya, terutama dalam hal pengumpulan dana zakat harus menggunakan strategi fundraising yang tepat dan efektif agar dana dapat terserap secara optimal. 


\section{H5: Kesadaran berpengaruh terhadap Minat Berwakaf Uang}

Dari hasil penelitian terhadap pengaruh kesadaran terhadap minat berwakaf uang. Nilai Tstatistik kesadaran sebesar $6.441<1.96$ atau dapat dilihat $\mathrm{p}$ value yang bernilai $0.000<0.05$. nilai original sampel adalah positif sebesar 0.600 yang menunjukan arah hubungan antara kesadaran terhadap minat berwakaf uang adalah positif.

Hasil penelitian ini sesuai dengan penelitian sebelumnya oleh Indri Kartika dan Ahmad Izzudin, dimana dibuktikan dengan hasil menunjukkan bahwa kesadaran berpengaruh positif terhadap minat berwakaf uang. semakin tinggi tingkat religiusitas seseorang belum tentu memiliki jiwa sosial yang tinggi, yang menimbulkan kesadaran. Pendapatan berpengaruh terhadap minat membayar zakat melalui kesadaran disimpulkan bahwa semakin tinggi tingkat kesadaran mempengaruhi minat di dalam berwakaf uang.

\section{H6: Religiusitas berpengaruh terhadap Minat Berwakaf Uang Melalui Kesadaran}

Dari Hasil penelitian hipotesis keenam terhadap pengaruh religiusitas terhadap kesadaran melalui minat berwakaf uang. dalam penelitiannya menemukan bahwa fundraising berpengaruh positif dan signifikan terhadap minat, Hal ini sesuai Nilai T-statistik kesadaran sebesar $2.169<1.96$ atau dapat dilihat $\mathrm{p}$ value yang bernilai $0.031<$ 0.05 .

Hasil penelitian ini sesuai dengan penelitian sebelumnya oleh Nanik Ermawati dan Zainal Afifi, Dimana dibuktikan dengan hasil menunjukkan bahwa religiusitas terhadap kesadaran melalui berwakaf uang berpengaruh positif terhadap minat berwakaf uang.

\section{H7: Fundraising Terhadap Kesadaran Melalui Minat Berwakaf Uang}

Dari hasil penelitian hipotesis ketujuh terhadap pengaruh fundraising terhadap kesadaran melalui minat berwakaf uang. dalam penelitiannya menemukan bahwa Nilai T-statistik kesadaran sebesar $3.414<1.96$ atau dapat dilihat $p$ value yang bernilai $0.001<0.05$. nilai original sampel adalah positif sebesar 0.331 yang menunjukan arah fundraising terhadap minat berwakaf uang melalui kesadaran adalah positif.

Hal ini sesuai dengan teori minat yaitu dengan motif sosial dapat membangkitkan kesadaran untuk melakukan aktivitas tertentu. Hal ini ditujukan dengan semakin giat strategi penggalangan dilakukan maka semakin besar keingintahuan dan kesadaran masyarakat akan pentingnya membangun ekonomi Islam dan membangkitkan minat masyarakat untuk berwakaf uang.

\section{Kesimpulan}

Penelitian ini menyimpulkan bahwa pertama, religiusitas berpengaruh terhadap kesadaran berwakaf uang pegawai kantor wilayah Kementerian Agama Provinsi Sumatera Selatan. Kedua, fundraising berpengaruh terhadap kesadaran pegawai kantor wilayah Kementerian Agama Provinsi Sumatera Selatan. Ketiga, religiusitas tidak berpengaruh terhadap minat berwakaf uang pegawai kantor wilayah Kementerian Agama Provinsi Sumatera Selatan. Keempat, fundraising berpengaruh terhadap minat berwakaf uang pegawai kantor wilayah Kementerian Agama Provinsi Sumatera Selatan. Kelima, kesadaran berpengaruh terhadap minat berwakaf uang pegawai kantor wilayah Kementerian Agama Provinsi Sumatera Selatan. Keenam, kesadaran berpengaruh terhadap 
kesadaran pegawai kantor wilayah Kementerian Agama Provinsi Sumatera Selatan. Ketujuh, kesadaran berpengaruh terhadap kesadaran pegawai kantor wilayah Kementerian Agama Provinsi Sumatera Selatan.

\section{Daftar Pustaka}

Alfisyah, N. (2018). PENGARUH AKTIVITAS FUNDRAISING ZAKAT BADAN AMIL ZAKAT NASIONAL (BAZNAS) KABUPATEN BENGKALIS TERHADAP MINAT MASYARAKAT DALAM MEMBAYAR ZAKAT. Universitas Islam Negeri Sultan Syarif Kasim Riau.

Amin, K. (2020). Regulasi Wakaf Indonesia. Direktorat Jenderal Bimbingan Masyarakat Islam.

Fazri, P. P. N., \& Saepulloh, A. (2019). ANALISIS STRATEGI FUNDRAISING BAZNAS KABUPATEN SUMEDANG DALAM MENINGKATKAN KESADARANMUZAKKI MELALUI LEMBAGA PENGELOLA ZAKAT.

Jalaludin. (1995). Psikologi Agama. Raja Grafindo Persada.

Muzarie, M. (2011). Sukses Memberdayakan Wakaf di Pesantren Modern Gontor. P3I STAI.

Nurfaidah, M. (2016). Wakaf Dan Pemberdayaan Ekonomi Syariah. Al-'Adl, 9(1), 146-161.

Rozalinda. (2015). Manajemen Wakaf Produktif. Raja Grafindo Persada.

Sidiq, H. A. (2015). Pengaruh Pengetahuan Zakat, Tingkat Pendapatan, Religiusitas Dan Kepercayaan Kepada Organisasi Pengelola Zakat Terhadap Minat Membayar Zakat Pada Lembaga Amil Zakat:(Studi Kasus Terhadap Muzakki di Fakultas Agama Islam dan Fakultas Ekonomi dan Bisnis Univ. Universitas Muhammadiyah Surakarta.

Ulya, Z. N. (2017). Pengaruh pengetahuan dan religiusitas terhadap pembayaran zakat profesi aparatur sipil negara di Kantor Wilayah Kementerian Agama Provinsi Jawa Tengah. UIN Walisongo. 